\title{
Breaking the Sound Barrier: Cuba's Cochlear Implant Program
}

\section{By Gloria Giraldo, MPH}

The sound of rain hitting the window may not be a transcendental event for most people, but for wide-eyed toddler and cochlear implant user María Alejandra Larred, it makes her shout at the top of her lungs, "Agua!" (Water!) eliciting a resounding cheer from all present. Unfortunately, this scene of aural awakening is out of reach for many hearing impaired children, particularly in developing countries.

Globally, in 2000, an estimated 62 million children under age 15 years had some degree of hearing loss, two-thirds of them in low- and middle-income countries.[1,2] Hearing loss is measured in decibels and categorized as mild, moderate, moderately severe, severe, and profound, according to an algorithmic scale. However, these categories may not accurately reflect real-life challenges a child faces. Severe and profound hearing loss may mean complete social isolation, limiting a child's opportunities and quality of life.[3,4]

The benefits of early detection and intervention are well documented and known to greatly increase deaf children's chances of developing their abilities to the fullest and enjoying a better quality of life.[5-8] One such intervention is cochlear implantation, specifically designed to treat severe to profound bilateral sensorineural hearing loss. Cochlear implants $(\mathrm{Cl})$ have transformed the outlook for severely and profoundly deaf children by providing them access to spoken language and environmental sound, in some cases for the first time.

According to the US Food and Drug Administration, nearly 188,000 children and adults worldwide have received implants, [9] the majority in high-income countries due to the high cost of the device-US\$15,000 to $\$ 35,000$-plus surgery, rehabilitation and long-term management-including device maintenance, parts and repairs.[10] For developing countries and most poor families in general, the cost barrier cannot be overemphasized. In addition, the World Health Organization does not recommend implantation "unless the necessary medical, educational, technical and psychological, and hearing therapist resources are available."[11] Only a handful of middleincome countries-China, Saudi Arabia, Iran, Egypt, and Malaysia-have $\mathrm{Cl}$ programs supported by public funding.[10] In Latin America, only Argentina, Brazil, Colombia, Costa Rica and Mexico have public financing schemes providing cochlear implantation to some low-income children.[12-15] Cuba is one of the few countries that has a comprehensive national program providing eligible children with a continuum of care that includes diagnosis, surgery, rehabilitation, and educational services, all free of charge to patients and their families.

\section{COCHLEAR IMPLANTATION IN THE CUBAN PUBLIC HEALTH SYSTEM}

Cuba's $\mathrm{Cl}$ program is part of a comprehensive hearing loss prevention strategy within the national public health system. At the primary prevention level, this strategy ensures prenatal care, genetic counseling, and immunization against rubella, mumps and meningitis, as well as universal access to treatment for otitis media, a major cause of hearing loss in developing countries.[16] Even so, approximately 300 babies are born annually in Cuba with profound bilateral hearing loss, and more suffer acute or progressive hearing loss from other causes during childhood.

At the secondary prevention level, a two-step, multi-targeted screening and early detection program has been in place since 1983. In Step 1, children are clinically selected using a variety of risk criteria, including family history of hearing impairment, infectious or ototoxic drug therapy during pregnancy, severe fetal distress, and recurrent otitis media. Groups targeted for Step 2 screening include high-risk newborns and other children under age 3 years referred from intensive care units or primary care services.[17] At the tertiary level, corrective surgery, hearing aids and prostheses (including $\mathrm{Cl}$ ), and rehabilitation are provided. 


\section{Feature}

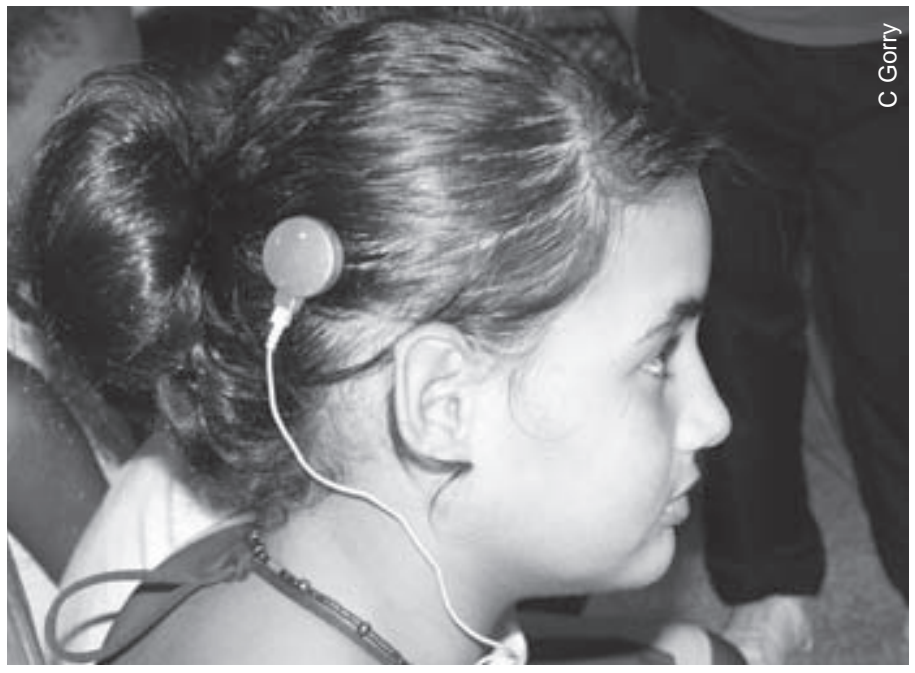

A total of 165 Cuban children have been fitted with cochlear implants.

The $\mathrm{Cl}$ program is coordinated by the National Cochlear Implant Group, a team of otosurgeons, audiologists, neurophysiologists, speech-language pathologists, speech therapists, geneticists, anesthesiologists, educational psychologists, pediatricians, neuropediatricians, and a Ministry of Education representative, headquartered in Havana.

In 1998, the first multichannel implant surgeries were performed in adults in Cuba. "During the program's formative years, we focused on building technical skills and familiarizing ourselves with the technology," explained Dr Beatriz Bermejo, speech-language pathologist with the national group. Cuban surgeons received specialized otosurgery training from experienced teams in Colombia, Spain, the United States, and Venezuela.

When the National Cochlear Implant Group was formed in 2000, the decision was made to focus exclusively on children. "In a resource-constrained context like ours, the health system prioritizes children as a policy in general and for cochlear implantation specifically, since children have shown the best prognosis," said Dr Eduardo Morales, Group Coordinator. In 2002, the first children under age 5 years were fitted with $\mathrm{Cl}$, and by 2005, 21 children had been fitted throughout the country.

To date, 417 children have undergone comprehensive evaluation for cochlear implantation. Of those, 165 have received implants and are undergoing rehabilitation and long-term management. Follow-up data shows that $71 \%$ of these implant users have made significant progress in language development as measured by a battery of audiometric and speech perception tests.[18]

While all implant surgery is performed in Havana, smaller implant groups in Cuba's 13 other provinces are responsible for local audiologic follow-up and rehabilitation for children in their territories. Each provincial group includes an audiologist, speech-language pathologist, neurophysiologist, social worker and a Ministry of Education delegate. "While cochlear implantation is a surgical procedure within a medical context, improving quality of life for implant recipients is only possible by involving a range of professionals," Dr Morales explained.

\section{SELECTION AND REFERRAL PROCESS}

Given the high cost and invasiveness of implant surgery, combined with rehabilitation and long-term management, selection criteria are designed to identify children who will benefit most from implantation. General criteria include children aged 18 months to 18 years with audiologically confirmed hearing impairment $\geq 80$ decibels for whom hearing aids do not work. Hearing impaired children are first referred to a provincial implant group, usually by a physician, sometimes by a Ministry of Education regional diagnostic center where all school-aged children with disabilities are assessed to determine appropriate grade level and type of school, and occasionally by parents. The provincial groups refer children to the national group in Havana for comprehensive assessment, including audiologic, radiologic, neurophysiologic and other medical evaluations to determine degree and cause of hearing loss, and detect associated anomalies and potential surgical risks.

A psychological team also evaluates each child's family and home environment, providing support and therapy to help parents make an informed, shared decision about implantation. Should they choose this option, the same team helps them prepare to work with the child during the long rehabilitation phase.

"Family members may have the misconception that an implant will convert their deaf child into a normal-hearing child overnight," explained psychologist Lourdes Hernández. "Therefore, we work intensively with families to adjust their expectations and help them better understand the implantation and rehabilitation process." Dr Morales added, "We know, and the evidence shows, that a supportive and engaged family is key to implantation success."

In younger children especially, evaluation may take several months to rule out the benefit of hearing aids. A child with some residual hearing is usually fitted with a digitally-programmed hearing aid and reevaluated after 3 to 6 months. If progress is evident with the hearing aid, the child will continue to be monitored but not be fitted with an implant.

Three types of patients are prioritized for implantation: children with acute hearing loss due to bacterial meningitis, children with multiple impairments, and postlingual children with sudden or progressive hearing loss due to other causes. Although bacterial meningitis is rare in Cuba,[19] one of the most devastating sequelae is profound hearing loss with rapid cochlear ossification. Such was the case of Lianelys Pérez, who contracted meningitis in 2007 at 7 months old. Before this, no child younger than 12 months had ever been fitted with an implant in Cuba, but certain ossification from the infection compelled the implant team to act quickly. Lia's mother described the anguish and impotence she felt upon learning that her daughter had lost her ability to hear: "I was afraid my child was going to live in a world of silence all her life."

When Lia's pediatrician presented cochlear implantation as an option, her parents were fearful, since Lia would be the youngest child to undergo the surgery in Latin America. However, after intensive consultation with the National Implant Group, "We automatically became part of the team," said Israel Pérez, Lia's father. "We were briefed on the risks and potential benefits of the surgery, on the research that had been done, and on the commitment to rehabilitation that was required from us. We agreed and know that, as parents, we are fundamental to our daughter's progress." 


\section{Feature}

Today, Lia's milestones amaze them. "Just yesterday, she picked up the phone, and when I asked who it was, just to practice with her, she surprised me by saying, 'It's Daddy.' It was the first time in her life she had identified a voice over the phone," said her mother, visibly moved. Lia is now 3 years old and speaks fairly clearly in phrases at near age-level standards, allowing her to communicate swiftly with peers at her mainstream pre-school.

Regarding children with multiple disabilities, Dr Morales explained, "We are well aware that from a cost-effectiveness perspective, children with multiple disabilities may not be optimal implant candidates. However, from a quality-of-life perspective, deaf and blind children, and those with other multiple disabilities have much to gain." According to Dr Bermejo, in addition to routine audiometric testing, speech perception, expressiveness, social skills, and social integration assessments are performed pre- and post-surgery at 3-month intervals during the first year, at 18 and 24 months, and at 3 and 5 years of age. Results reveal that, although perceptual skills improve more slowly for children who are both blind and deaf compared to those suffering hearing loss alone, $47 \%$ of blind-and-deaf $\mathrm{Cl}$ users in Cuba have shown functional progress as measured by the Profile of Actual Linguistic Skills (PALS).

\section{SURGERY, INITIAL PROGRAMMING, LONG-TERM MANAGEMENT}

The Cuban program currently uses US- and Australian-manufactured devices.[20] The 2 to 3 hour operation is performed in a special service created at the Marfán Municipal Children's Hospital in Havana. In a study of 138 pediatric $\mathrm{Cl}$ users during the first 12 months postimplant, 10 reported complications from device failures (4), immediate post-surgical complications (3), and late on-set infections (3). Re-implantation was successful in those who required it.[21]

Four weeks after surgery, the implant is programmed, and the patient is exposed to sound for the first time. During the first 3 months, the device is fine-tuned to the child's particular stimulation needs at least once a week. Throughout the first year, audiologists monitor the device and adjust stimulation levels if necessary at least once every 3 months, and during the second year at least once every 6 months. Such programming and re-programming are part of the long-term management required by implant users.

All repairs and replacement parts are covered by the National Cochlear Implant Program. Providing a child from a remote rural area with a cochlear implant may also mean addressing basic needs, such as a stable electricity supply to keep the device's batteries recharged. Additionally, the program covers all transportation and lodging for the children, their parents, and occasionally a special education teacher accompanying them, during each phase of implantation (pre-surgical assessment, surgery, and rehabilitation).

\section{REHABILITATION}

Results of pediatric $\mathrm{Cl}$ use depend on multiple factors including age at implantation, time elapsed since onset of hearing loss, causes and type of hearing impairment, neural plasticity, implant programming (hearing maps), actual implant use, family support, and speech and educational rehabilitation. Children fitted with $\mathrm{Cl}$ may require at least 4 years of intensive therapy to fully benefit. $[6,22,23]$ After the device is programmed and fine-tuned, the child begins a 3-month intensive rehabilitation program led by a speech

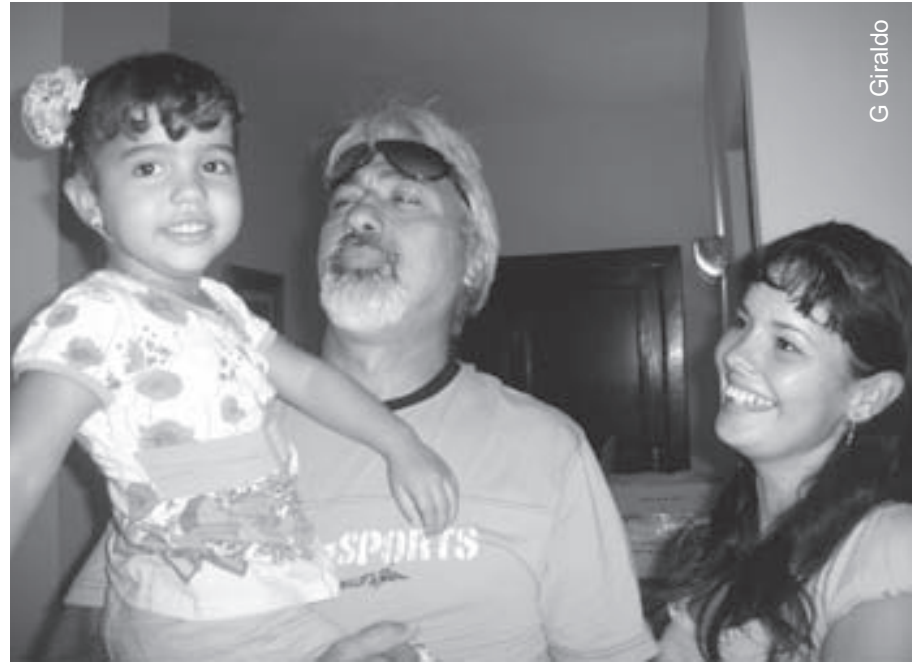

Lianelys Pérez, age 3, with her parents. Lia received a cochlear implant at age 11 months and now attends regular preschool.

therapist and speech-language pathologist using a combination of cognitive and speech therapies. Rehabilitation continues with 4 one-hour sessions weekly for at least one year, depending on each child's progress.

For Ana Esther Díaz, whose 10-year-old daughter Daylene has been deaf since birth, progress takes many forms. "Today, 3 years after her implant, we feel much closer to each other; she is very motivated. We know she still has a long way to go, but the implant has given her a way to hear and has transformed our lives." Since Daylene had learned some sign language before the implant, she continues to learn through a bimodal approach using both oral and sign language. As Dr Bermejo explained, "Our goal is to enhance their communication code, so we don't take anything away from skills they already have; on the contrary, we want to maximize their communication potential. We use a total communication approach."

Parents receive training and support to continue rehabilitation at home. In the case of Danielito, a deaf-and-blind child who received an implant at age 3 , the entire family has been actively engaged in "opening the world of sound," for him, as his grandfather Rubén Rodríguez explained. "We had to be careful, though, because, due to his blindness, every new sound surprised him. Announcing a new sound beforehand so he wouldn't be startled was part of the process...We try to stimulate his need to communicate by exposing him to new sounds frequently," Rodríguez added. "He especially enjoys all kinds of music, from children's songs to classical music, even reggaeton. We make up songs about all the things around him. We have the 'water song,' the 'air song,' the 'hurricane song,' the 'house song'... How he loves children's stories! He spends hours memorizing them and then narrating them back to us as much as he can. He uses oral language to communicate, along with a form of the Tadoma method, which entails placing his hand on the speaker's throat to feel the vibrations."

Families may also participate in a support group that meets regularly, and all implant users and their families can go to an annual summer camp that helps create a greater sense of community. 


\section{EDUCATION AND INCLUSION}

Rehabilitation and education go together. Ideally, an individualized communication strategy is designed for each child's needs and abilities, drawing on oral, sign language, bimodal (oral and sign), tactile sign language, lip reading, and Braille techniques. The goal is to impart a grade-level curriculum so the child receives as complete an education as possible.

Integrating $\mathrm{Cl}$ users in both special education and mainstream classrooms has posed challenges, however. Most special education teachers in Cuba have been trained to help hearing impaired students learn sign language rather than integrate hearing, language, and speech. Now they need additional training to help children with implants develop spoken language through listening. Likewise, teachers in mainstream schools need to adapt curriculum to facilitate integration of implant users in the classroom. Both types of training require close coordination among educators, audiologists, speech-language pathologists and other specialists. Teachers in both settings currently attend workshops on methods for working with $\mathrm{Cl}$ users, but achieving effective intersectoral cooperation to meet these needs has taken time. According to Teresa Morales, educational psychologist with the National Cochlear Implant Group, "We are working on creating standardized curricula and evaluation instruments to better monitor the educational transition and progress of implanted children."

\section{THE ROAD AHEAD}

Against economic odds, Cuba has adapted best practices from around the world to build a comprehensive $\mathrm{Cl}$ program that reflects the country's medical and technological capacity, health care priorities, and comprehensive approach to disability prevention and rehabilitation. There are still many hurdles to overcome, however, not the least of which is assuring sustainability. Expand- ing the program to benefit more children as well as adults will also depend on future economic conditions.

Among the most immediate priorities are training additional surgeons and decentralizing some vital services, such as audiologic assessments, and device programming and maintenance. Three regional centers in Camagüey, Granma, and Villa Clara provinces are expected to open in 2010 so that provincial implant users can receive these services closer to home.

\section{Cuban Children with Cochlear Implants in School, 2009}

\begin{tabular}{l|c|}
\hline Type of School & No. of Students \\
\hline Special Education (all levels) & 70 \\
Mainstream Education & \\
Pre-school & 6 \\
Elementary & 54 \\
Middle school & 17 \\
Vocational school & 4 \\
High school & 3 \\
University & 4 \\
Total & 158
\end{tabular}

Source: Chkout T and National Cochlear Implant Group. Atención educativa a los niños sordos y sordociegos con implante coclear en Cuba. Desafíos. First CubanIbero American Cochlear Implant and Related Sciences Symposium; 2009 Oct 28-30; Havana, Cuba.

Several studies are currently underway, including research on progress being made by $\mathrm{Cl}$ users with multiple disabilities-a unique developing country experience. Researchers, program staff and all families involved hope that dissemination of the results will bolster visibility of the program and lead to further international cooperation-presaging more aural awakenings, like María Alejandra's joyous discovery of the sound of raindrops on a window pane. -1 -

\section{References \& Notes}

1. Olusanya BO, Newton VE. Global burden of childhood hearing impairment and disease control priorities for developing countries. Lancet. $2007 \mathrm{Apr}$ 14:369(9569):1314-7.

2. The World Health Organization estimates that in 2005 there were 278 million people in the world with disabling hearing impairment; of these, hearing loss began in childhood in 68 million people.

3. World Health Organization. Primary Ear and Hearing Care Training Resource: Advanced Level [monograph on the Internet]. Geneva: WHO; 2006 [cited 2009 Dec 8]. Available from: http://www.who.int/pbd/deafness/activities/hearing_care/advanced.pdf

4. Pascolini D, Smith A. Hearing Impairment in 2008: A compilation of available epidemiological studies. Int J Audiol. 2009;48(7):473-85.

5. Fortnum HM, Marshall DH, Summerfield AQ. Epidemiology of the UK population of hearing-impaired children, including characteristics of those with and without cochlear implants-audiology, aetiology, comorbidity and affluence. Int J Audiol. 2002 Apr;41(3):170-9.

6. Archbold S, O'Donoghue GM. Cochlear implants in children current status. J Paediatric Child Health. 2009;19(10):457-63.

7. Fitzpatrick E, Olds J, Durieux-Smith A, McCrae R, Schramm D, Gaboury I. Pediatric cochlear implantation: How much hearing is too much? Int J Audiol. 2009 Feb;48(2):91-7

8. Joint Committee on Infant Hearing. Year 2007 Position Statement: Principles and guidelines for early hearing detection and intervention programs. Pediatrics. 2007 Oct;120(4):898-921.

9. National Institute on Deafness and Other Communication Disorders [homepage on the Internet]. Bethesda: USA; [updated 2009 Aug; cited 2009 Dec 10]. Available from: http://www.nidcd.nih.gov/health/hearing/coch.asp

10. Khan MI, Mukhtar N, Saeed SR, Ramsden RT. The Pakistan (Lahore) cochlear implant programme: issues relating to implantation in a developing country. $\mathrm{J}$ Laryngol Otol. 2007 Aug;121(8):745-50. Epub 2007 Apr 20.

11. World Health Organization. Prevention of Blindness and Deafness. Guidelines for hearing aids and services for developing countries [monograph on the In- ternet]. 2nd ed. Geneva: WHO; 2004 [cited 2009 Dec 8]. Available from: http:// www.who.int/pbd/deafness/en/hearing_aid_guide_en.pdf

12. Berruecos P. Cochlear implants: an international perspective-Latin American countries and Spain. Audiology. 2000 Jul-Aug;39(4):221-5.

13. Dr Adriana Rivas (Colombia). Personal communication.

14. Dr Pedro Berruecos (Mexico). Personal communication.

15. Dr Julian Chaverri (Costa Rica). Personal communication

16. Tarabichi MB, Todd C, Khan Z, Yang X, Shehzad B, Tarabichi MM. Deafness in the developing world: The place of cochlear implantation. J Laryngol Otol. 2008 Sep;122(9):877-80.

17. Pérez-Abalo MC, Gaya-Vázquez JA, Savio-López G, Perera-González M, Ponce de León M, Sánchez-Castillo M. A 25-year review of Cuba's screening program for early detection of hearing loss. MEDICC Review. 2009 Winter;11(1): 22-8.

18. Scales used include Meaningful Auditory Integration Scale (MAIS), the Ling Sound Test, and the Early Speech Perception Test (ESP) for Profoundly Hearing-Impaired Children.

19. According to the Ministry of Public Health, in 2008, incidence of meningococcal meningitis was 0.1 per 100,000 population, pneumococcal meningitis was 0.6 per 100,000 population, and haemophilus meningitis type $b$ was negligible. See Anuario Estadístico de Salud 2008, available from: http://www.sld.cu/galerias/pdf/sitios/dne/anuario_2008_5e.pdf

20. Advanced Bionics obtained a specific license from the US Department of Commerce to sell cochlear implant devices to the Cuban program.

21. Dr Ulíses Rodríguez, otosurgeon, Cuban National Cochlear Implant Group presentation at International Cochlear Symposium, Havana, Cuba October 28-30, 2009.

22. Bond M, Mealing S, Anderson R, Elston J, Weiner G, Taylor RS, et al. The effectiveness and cost-effectiveness of cochlear implants for severe to profound deafness in children and adults: a systematic review and economic model. Health Technol Assess. 2009 Sep;13(44):1-30.

23. Geers AE. Factors influencing spoken language outcomes in children following early cochlear implantation. Adv Otorhinolaryngol. 2006;64:50-65. 